\title{
Photochemical and Antioxidant Responses in the Leaves of Xerophyta viscosa Baker and Digitaria sanguinalis L. under Water Deficit
}

Yasemin Ekmekci ${ }^{\mathrm{a}}$, Andreas Bohms ${ }^{\mathrm{b}}$, Jennifer A. Thomson ${ }^{\mathrm{c}}$, and Sagadevan G. Mundree ${ }^{\mathrm{c}, *}$

a Department of Biology, Faculty of Science, University of Hacettepe, Beytepe Campus 06532 Ankara, Turkey

b Fachbereich 5 - Biotechnology, University of Applied Science Berlin, Forum Seestraße, 13347 Berlin, Germany

c Department of Molecular and Cell Biology, University of Cape Town, Private Bag, Rondebosch, 7701, South Africa. Fax:+27 (21)6897573. E-mail: mundree@science.uct.ac.za

* Author for correspondence and reprint requests

Z. Naturforsch. 60 c, 435-443 (2005); received September 30/December 1, 2004

In this study, photochemical and antioxidant responses of the monocotyledonous resurrection plant Xerophyta viscosa Baker and the crab grass Digitaria sanguinalis L. under water deficit were investigated as a function of time. Water deficit was imposed by withholding irrigation for $21 \mathrm{~d}$. Gas exchange and chlorophyll a fluorescence analyses indicated that the dehydration treatment caused photoinhibition in both species. The reduction in the photosynthesis rate in both species during water deficit probably contributed to the decline in the photochemical efficiency of PSII and electron transport rate. However, the stomatal conductance of both species did not change during treatment whereas the intercellular $\mathrm{CO}_{2}$ pressure increased after $10 \mathrm{~d}$ of water deficit treatment. These observations could be related to nonstomatal limitations. The increasing net transpiration rate of both species may have contributed to leaf cooling because of water limitations. Prolonged water deficit resulted in photosynthetic pigment chlorophyll $(\mathrm{a}+\mathrm{b})$ and carotenoids content loss in only D. sanguinalis. Both species especially $D$. sanguinalis had increased the level of anthocyanin after $15 \mathrm{~d}$ of treatment, possibly to prevent the damaging effect of photooxidation. The total SOD activity of $D$. sanguinalis was significantly different from $X$. viscosa during the treatment. The total peroxidase activity in D. sanguinalis was significantly higher than in $X$. viscosa. X. viscosa acclimated to water deficit with no ultimate apparent oxidative damage due to endogenous protective mechanisms of resurrection. In case of $D$. sanguinalis, water deficit induced considerable stress and possibly caused some oxidative damage, despite the upregulation of protection mechanisms.

Key words: Xerophyta viscosa, Digitaria sanguinalis, Water Deficit

\section{Introduction}

Water deficit is one of the most important environmental stress factors, which can cause various types of physiological response and oxidative damage in plants. Most of the damage is associated with the photosynthetic process of the plant, which can be affected by light as well as water deficit. When plants are exposed to prolonged water deficit, they often decrease the rate of photosynthesis mainly due to stomatal closure and may limit photosynthetic $\mathrm{CO}_{2}$ fixation (Lawlor, 1995). Whatever the case, limitation of $\mathrm{CO}_{2}$ assimilation precedes inactivation of electron transfer reactions, reduction of photosynthetic electron transport may result in the formation of reactive oxygen species (ROS), such as superoxide $\left(\mathrm{O}_{2}^{-}\right)$, hydroxyl radicals $(\mathrm{OH} \cdot)$, and hydrogen peroxide $\left(\mathrm{H}_{2} \mathrm{O}_{2}\right)$ (Asada,
1999). ROS can lead to photoinhibitory and photooxidative damage in the photosynthetic apparatus (Asada, 1999). Photosystem II (PSII) in particular has been shown to be very sensitive to water deficit stress (Saccardy et al., 1998). The formation of ROS within the cell, in particular within the chloroplast, may increase in water stressed leaves, leading to lipid peroxidation, which ultimately causes membrane damage (Tambussi et al., 2000).

Plants have several protection mechanisms in order to prevent the damaging effect of photoinhibiton and of ROS. They can prevent the absorption of excess light by the production of sun-screen pigments (carotenoids and anthocyanins) (Sherwin and Farrant, 1998). Additionally, plants have evolved a series of non-enzymatic (glutathione, ascorbate, $\alpha$ tocophenol) and enzymatic [superoxide dismutase 
(SOD), glutathione reductase (GR), ascorbate peroxidase (APX), peroxidase (POD) and catalase (CAT)] antioxidants to cope with water deficit and avoid photooxidative damage, either by stress avoidance or stress tolerance (Foyer and Mullineaux, 1994). SODs are metalloproteins that catalyse the dismutation of superoxide radicals to $\mathrm{H}_{2} \mathrm{O}_{2}$ and $\mathrm{O}_{2}$ and play a major role in the defence against superoxide-derived oxidative stress in plant cells (Bowler et al., 1992). In addition, detoxification of cellular $\mathrm{H}_{2} \mathrm{O}_{2}$ through the activity of the AsadaFoyer-Halliwell scavenging cycle is an important step in the defence mechanisms against reactive oxygen species. The cycle found in chloroplasts and the cytosol involves the oxidation and reduction of ascorbate and glutathione through the activation of enzymes such as APX and GR (Foyer and Mullineaux, 1994; Noctor and Foyer, 1998). APX catalyses the reaction of ascorbate with $\mathrm{H}_{2} \mathrm{O}_{2}$ and GR catalyses the regeneration of ascorbate. Under water deficit condition, an increase in activities of antioxidant enzymes to overcome the increased photooxidative stress, has been reported recently (Lima et al., 2002; Srivalli et al., 2003; Jung, 2004; Ramachandra-Reddy et al., 2004; Pinheiro et al., 2004).

Xerophyta viscosa Baker (family Velloziaceae) is a monocotyledonous resurrection plant that can withstand severe environmental stresses such as dehydration, high temperature, chilling and high light (Mundree et al., 2000; Mowla et al., 2002; Garwe et al., 2003; Ekmekci et al., 2004). Molecular, biochemical and physiological approaches have been used to obtain a greater insight into the mechanism of abiotic stress tolerance in this extremophile (Sherwin and Farrant, 1996, 1998; Mundree and Farrant, 2000; Mundree et al., 2000; Ndima et al., 2001; Mowla et al., 2002). X. viscosa can be dehydrated to $5 \%$ relative water content and upon rewatering the desiccated plant rehydrates completely within $80 \mathrm{~h}$, resuming full physiological activities (Sherwin and Farrant, 1996). Digitaria sanguinalis L. (family Poaceae) is a grass that grows widely in South Africa. It is sensitive to abiotic stresses such as water deficit (Sionit and Patterson, 1985) and high light (Ekmekci et al., 2004) and is thus an excellent system to use for comparison with $X$. viscosa.

The aim of this study was to evaluate the photochemical responses of $X$. viscosa and $D$. sanguinalis to water deficit, both in terms of net photosynthesis and transpiration rate, stomatal conductance and intercellular $\mathrm{CO}_{2}$ pressure and photosynthetic efficiency of PSII. Additionally, the response of protec- tive pigments as well as some antioxidant enzymes was investigated to determine whether they played a role in the acclimation mechanisms of $X$. viscosa and $D$. sanguinalis to water deficit conditions.

\section{Materials and Methods}

\section{Plant material and experimental conditions}

Xerophyta viscosa Baker plants collected from the Cathedral Peak Nature Reserve (Kwazulu-Natal Province, South Africa) and Digitaria sanguinalis collected from the grounds of the University of Cape Town (Western Province, South Africa) were used in this comparative study. $X$. viscosa and $D$. sanguinalis plants were grown in a phytotron at $25^{\circ} \mathrm{C} / 17^{\circ} \mathrm{C}$, with a photon flux density of $500 \mu \mathrm{mol} \mathrm{m}{ }^{-2} \mathrm{~s}^{-1}$ in a $16 \mathrm{~h}$ light $/ 8 \mathrm{~h}$ dark photoperiod. Both species were watered to full turgor prior to the commencement of the experiment. All of the parameters measured at this time were accepted as parameters of $0 \mathrm{~d}$ (untreated). Water deficit was imposed by withholding irrigation for $21 \mathrm{~d}$. Water deficit treatment periods were for $0 \mathrm{~d}$ (untreated), 1 to $12 \mathrm{~d}$ (every second day) and 12 to $21 \mathrm{~d}$ (every third day). The effects of water deficit on $X$. viscosa and $D$. sanguinalis were investigated as a function of time. The leaves of both species were harvested at the end of each dehydration treatment period, at the same time for the duration of the study.

\section{Relative water content (RWC)}

The $R W C$ was calculated using the standard formula previously determined by Farrant (2000), where $F W, H y d W$ and $D W$ are the leaf fresh weight, hydrated (full turgor) and dry weights, respectively. The hydrated weight was determined by weighing the leaf after $24 \mathrm{~h}$ of immersion in distilled water in a sealed flask at room temperature. The dry weight was determined gravimetrically by oven drying at $70{ }^{\circ} \mathrm{C}$ for $48 \mathrm{~h}$. Five leaf samples of both species were used in $R W C$ analyses at each of the dehydration treatment periods.

\section{Gas exchange measurements}

The measurements of gas exchange were made on nine randomly selected leaves of each species at various intervals during the dehydration treatment periods in a phytotron at $25^{\circ} \mathrm{C}$. The light saturated, net photosynthesis rate $\left(\mu \mathrm{mol} \mathrm{m}{ }^{-2} \mathrm{~s}^{-1}\right)$, transpiration rate $\left(\mathrm{mmol} \mathrm{m} \mathrm{m}^{-2} \mathrm{~s}^{-1}\right)$, stomatal con- 
ductance $\left(\mathrm{mol} \mathrm{H} \mathrm{O} \mathrm{m}^{-2} \mathrm{~s}^{-1}\right)$ and intercellular $\mathrm{CO}_{2}$ pressure ( $\mu$ bar) were measured using a LCA 3 (ADC Co. Ltd., Huddelston, UK) Infrared Gas Analyser (IRGA). The instrument was operated in differential mode, at an ambient $\mathrm{CO}_{2}$ pressure of $300 \mu$ bar. The parameters were calculated according to the equations of von Caemmerer and Farquhar (1981). Water use efficiency was calculated according to net photosynthesis rate/transpiration rate $(\mu \mathrm{mol} / \mathrm{mmol})$.

\section{Chlorophyll a fluorescence measurements}

Chlorophyll a fluorescence measurements were performed with a portable, modulated chlorophyll fluorescence analyzer (OS-500, Opti-Science, USA), on the same nine leaves used for gas exchange measurements in both species at the end of the dehydration treatment periods in a phytotron at $25^{\circ} \mathrm{C}$. Following $10 \mathrm{~min}$ dark adaptation, the minimal fluorescence $\left(F_{\mathrm{o}}\right)$, and the weak measuring light (about $4 \mu \mathrm{mol} \mathrm{m} \mathrm{m}^{-2} \mathrm{~s}^{-1}$ ) were recorded. Thereafter the leaf material was exposed to a $1 \mathrm{~s}$ saturating light with an intensity of approximately $7500 \mu \mathrm{mol} \mathrm{m}{ }^{-2} \mathrm{~s}^{-1}$ to obtain the maximum fluorescence $\left(F_{\mathrm{M}}\right)$ (Krause and Weis, 1991). The ratio of variable $\left(F_{\mathrm{V}}\right)$ to maximum fluorescence $F_{\mathrm{V}} / \mathrm{F}_{\mathrm{M}}$ was calculated as follows: $F \mathrm{~V} / F \mathrm{M}=\left(F_{\mathrm{M}}-F_{\mathrm{o}}\right) / F_{\mathrm{M}}$. In addition, the electron transport rate (ETR) through PSII was determined (Genty et al., 1989).

\section{Pigment analysis}

For each dehydration treatment period, photosynthetic pigments were extracted from five separate leaf samples in $100 \%$ acetone. The absorbance of the extracts was measured at 470, 644.8 and $661.6 \mathrm{~nm}$ using a Beckman DU-600 UV-Vis spectrophotometer. The content of chlorophyll $(\mathrm{a}+\mathrm{b})$ and carotenoids $(\mathrm{x}+\mathrm{c})$ was calculated using adjusted extinction coefficients (Lichtenthaler, 1987). Anthocyanins were extracted from leaf material (five replicates) in $1 \mathrm{ml}$ of acidified methanol [methanol/water/ $\mathrm{HCl}$ (79:20:1)] for $48 \mathrm{~h}$ at $4{ }^{\circ} \mathrm{C}$. The extract was then centrifuged for 1-2 s (Sherwin and Farrant, 1996). The absorbance was measured at 530 and $657 \mathrm{~nm}$ and the anthocyanin content was determined by: $A_{530}-$ (1/3 $\left.A_{657}\right)$ (Mancinelli et al., 1975).

\section{Preparation of crude enzyme extracts}

Aliquots (0.25 $\mathrm{g}$ for SOD and $0.25 \mathrm{~g}$ for POD) of control and dehydration treated leaves from both species were homogenised in a homogenisation buffer (92 mm Tris-HCl, pH 6.8, and 13.6\% glycerol) for $5 \mathrm{~min}$ (Burke and Oliver, 1992) for SOD enzyme or in $100 \mathrm{~mm}$ potassium phosphate buffer ( $\mathrm{pH} 7.8$ ) containing $0.1 \mathrm{~mm}$ EDTA, 1\% PVP-40 (Rao et al., 1995) for POD enzyme. The homogenate was then transferred to an Eppendorf tube and centrifuged at $18,000 \times g(1214 \mathrm{H}$ rotor in a Sigma $2 \mathrm{~K} 15$ centrifuge) for $20 \mathrm{~min}$ at $4{ }^{\circ} \mathrm{C}$ in a microcentrifuge. The supernatants were removed and concentrated using a freeze drier for $4 \mathrm{~h}$. After lyophilisation the supernatant was stored at $-70^{\circ} \mathrm{C}$ until used.

The protein concentration of the crude leaf extract was determined according to Bradford (1976).

\section{Determination of antioxidant enzyme activities}

The crude extracts of treated leaves from both species containing equal amounts of protein were subjected to discontinuous PAGE under non-denaturing conditions, using $5 \%$ stacking and $12 \%$ separating gels as described by Laemmli (1970). Electrophoretic separation was performed at $4{ }^{\circ} \mathrm{C}$ for approx. $3 \mathrm{~h}$ with a constant current.

Total SOD activity in extracts was determined using the staining technique of Burke and Oliver (1992). After electrophoresis the gels were transferred to a plastic container carrying $25 \mathrm{ml}$ of negative activity stain [50 mm potassium phosphate buffer (pH 7.5), $0.1 \mathrm{~mm}$ EDTA, 0.2\% v/v $N, N, N^{\prime}, N^{\prime}$-tetramethyl ethylene diamine (TEMED)]. $3 \mathrm{~mm}$ Riboflavin and $0.25 \mathrm{~mm}$ Nitroblue tetrazolium were added and the gels incubated by shaking in the dark for $45 \mathrm{~min}$. Following incubation, the gels were rinsed with and placed in distilled water and exposed to a high pressure lamp, $60 \mathrm{~cm}$ above the gel, generating a light intensity of $300 \mu \mathrm{mol} \mathrm{m}{ }^{-2} \mathrm{~s}^{-1}$, for approx. $15 \mathrm{~min}$ at $25^{\circ} \mathrm{C}$. The gels were then stored in $0.01 \mathrm{~m}$ acetic acid until an image was recorded. Total POD activity was determined by incubating gels in $0.2 \mathrm{M}$ sodium acetate buffer ( $\mathrm{pH} 4.5)$ containing $2 \mathrm{~mm}$ benzidine for $1 \mathrm{~h}$ at room temperature, with agitation. The reaction was initiated by adding $3 \mathrm{~mm}$ $\mathrm{H}_{2} \mathrm{O}_{2}$ and was allowed to continue for $20 \mathrm{~min}$ (Rao et al., 1995).

SOD and POD enzyme activities were determined using enzyme standards from bovine erythrocyte (EC 1.15.1.1) and horseradish peroxidase (EC 1.11.1.7), respectively. The sum of individual 
antioxidant enzyme activity bands was quantified with the Syngene software programme used by the Gene Genius Bio Imaging System. The sum of individual band activities of SOD and POD was determined by total activity (units $\mathrm{mg}^{-1}$ protein).

\section{Statistics}

The experiment was performed in a completely randomised design with two factors (species and water deficit treatments). Differences among the treatments as well as between the two species were tested using the Systat 10 statistical programme. Statistical variance analysis of the results was performed and compared with the least significant differences (LSD) at the 5\% level.

\section{Results and Discussion}

\section{Relative water content ( $R W C$ )}

In the first $10 \mathrm{~d}$ of the dehydration treatment the $R W C$ of $X$. viscosa and $D$. sanguinalis fluctuated between 75 and $90 \% R W C$ and 80 and $90 \%$ $R W C$, respectively. After $12 \mathrm{~d}$ without water supply the leaf water status of the non-watered plants started to decrease significantly (Fig. 1A). This result indicated that a water deficit stress was imposed on both species by the dehydration treatment.

\section{Gas exchange measurements}

The effect of water deficit on gas exchange parameters in $X$. viscosa and $D$. sanguinalis was investigated. The water deficit treatment (particularly after $8 \mathrm{~d}$ of dehydration treatment) led to a substantial reduction in the photosynthetic $\mathrm{CO}_{2}$ assimilation in both species (Fig. 1B). At the end of the dehydration treatment, the net photosynthesis rate of $X$. viscosa and $D$. sanguinalis decreased to $75 \%$ and $90 \%$, respectively. The net photosynthesis rate of $D$. sanguinalis was higher than in $X$. viscosa during $18 \mathrm{~d}$ of the dehydration. At the end of the dehydration treatment, the loss of $90 \%$ in the net photosynthesis rate of D. sanguinalis resulted in the death of the plants. The decrease of $75 \%$ in the net photosynthesis rate did not affect $X$. viscosa permanently. Following rehydration, $X$. viscosa was able to recover fully (data not shown). The stomatal conductance of $D$. sanguinalis increased during dehydration treatment (Fig. 1C). In $X$. viscosa an increase was only observed for the first $4 \mathrm{~d}$ of dehydration. Thereafter, the stomatal conductance returned to an ambient level, then decreased with increasing the time. The intercellular $\mathrm{CO}_{2}$ pressure of both species increased after a $10 \mathrm{~d}$ dehydration period, but this was particularly striking in $D$. sanguinalis (Fig. 1D). An increase of intercellular $\mathrm{CO}_{2}$ pressure was not accompanied by an increase of photosynthesis rate. Thus a decrease in the photosynthesis rate of both species could not be related to limited $\mathrm{CO}_{2}$ diffusion to intercellular spaces of leaves as a consequence of stomatal closure, probably related to impaired metabolism by direct inhibition of photosynthesis (non-stomatal limitation). The transpiration rate (in the light) in D. sanguinalis increased significantly after $12 \mathrm{~d}$ of water deficit, whereas in $X$. viscosa, the transpiration rate increased significantly initially and then decreased, and at the end of the treatment returned to its original level (Fig. 1E). This response may have contributed to leaf cooling because of water limitations. The increase in the transpiration rate and stomatal conductance together with a decline in the net photosynthesis rate resulted in the decline in water use efficiency in both species after $10 \mathrm{~d}$ of dehydration. It was concluded that a controlled shutdown of photosynthesis occurs at relatively high water contents in order to minimise photooxidation, as proposed in a previous study (Farrant, 2000). However, the decline of water use efficiency was significantly higher in $D$. sanguinalis compared to $X$. viscosa after $10 \mathrm{~d}$ (Fig. 1F). This was expected as $X$. viscosa is capable of tolerating severe desiccation $(5 \% R W C)$ (Sherwin and Farrant, 1996; 1998; Mundree and Farrant, 2000).

\section{Chlorophyll a fluorescence measurements}

To examine the effects of water deficit on the activity of PSII, changes in the photochemical efficiency $\left(F_{\mathrm{V}} / \mathrm{F}_{\mathrm{M}}\right)$ of PSII in $X$. viscosa and D. sanguinalis were measured (Fig. 2A). In the leaves of the untreated plants of $X$. viscosa and $D$. sanguinalis, the fully dark-adapted $F_{\mathrm{V}} / \mathrm{F}_{\mathrm{M}}$ ratios were 0.80 . With increasing the dehydration period the ratios decreased in both species. The $F_{\mathrm{V}} / \mathrm{F}_{\mathrm{M}}$ ratios had decreased only from day 10 and 6 of the dehydration treatment in $X$. viscosa and $D$. sanguinalis, respectively. These $F_{\mathrm{V}} / \mathrm{F}_{\mathrm{M}}$ ratios suggest a higher stability of PSII in $X$. viscosa. By the end of the dehydration treatment (21 d), a complete breakdown of the PSII activity of both species occurred and no noticeable photochemical efficiency was 


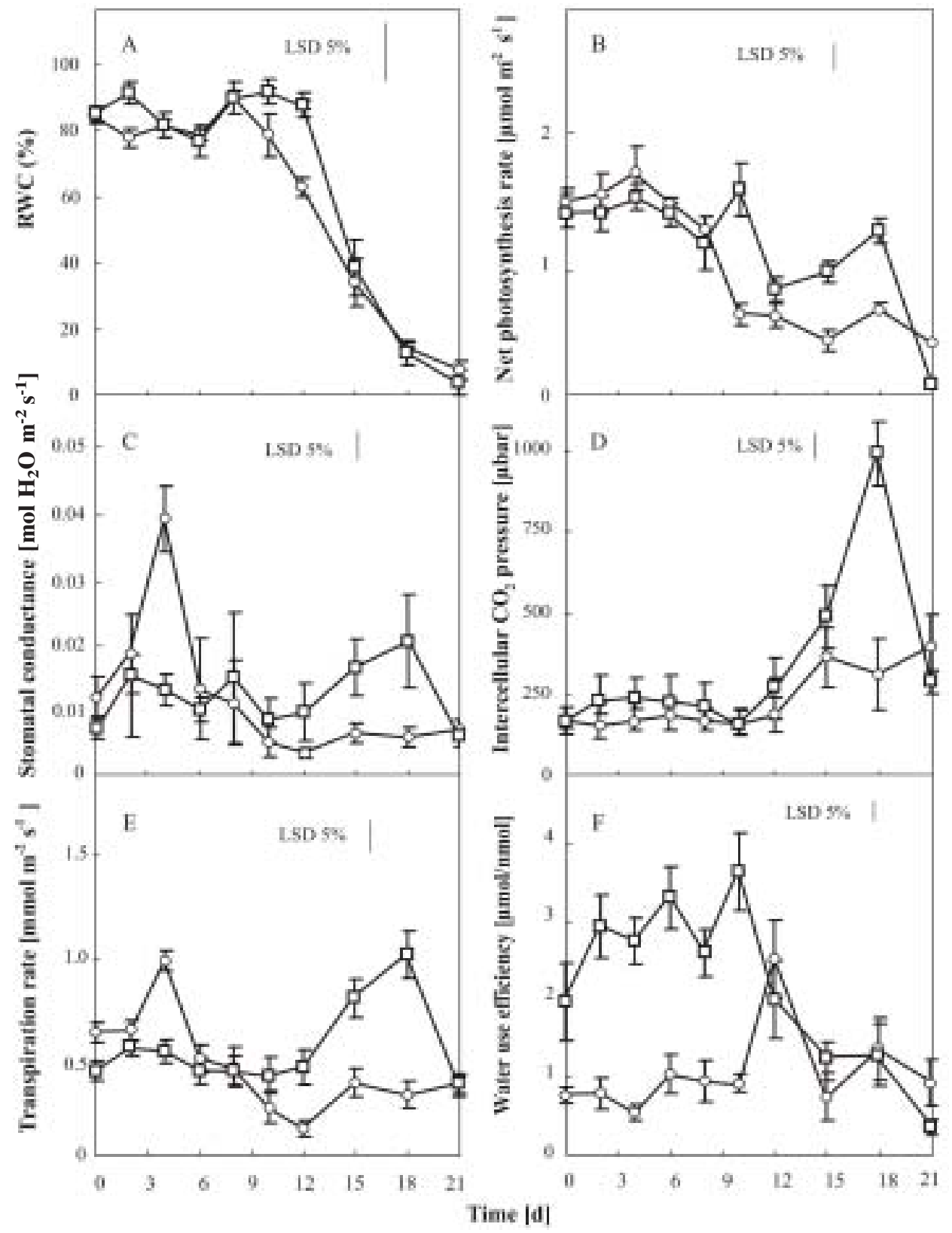

Fig. 1. Relative water content $(R W C)$ and gas exchange responses of $X$. viscosa $(\mathrm{O})$ and $D$. sanguinalis ( $\square)$ leaves exposed to water deficit; (A) $R W C$; (B) net photosynthesis rate; (C) stomatal conductance; (D) intercellular $\mathrm{CO}_{2}$ pressure; (E) transpiration rate (in the light); and (F) water use efficiency. The error bars represent \pm SE.

measurable. The electron transport rate (ETR) of $X$. viscosa and D. sanguinalis did not change significantly during the first $10 \mathrm{~d}$ and $12 \mathrm{~d}$ of treatment, respectively (Fig. 2B). With continued stress a significant decline in the electron transport rate was observed in both species which suggested a shut down or inhibition of the PSII reaction centres (Fig. 2B). The observation was strengthened by the decrease of the net photosynthesis rate due to non-stomatal limitation in both species. 


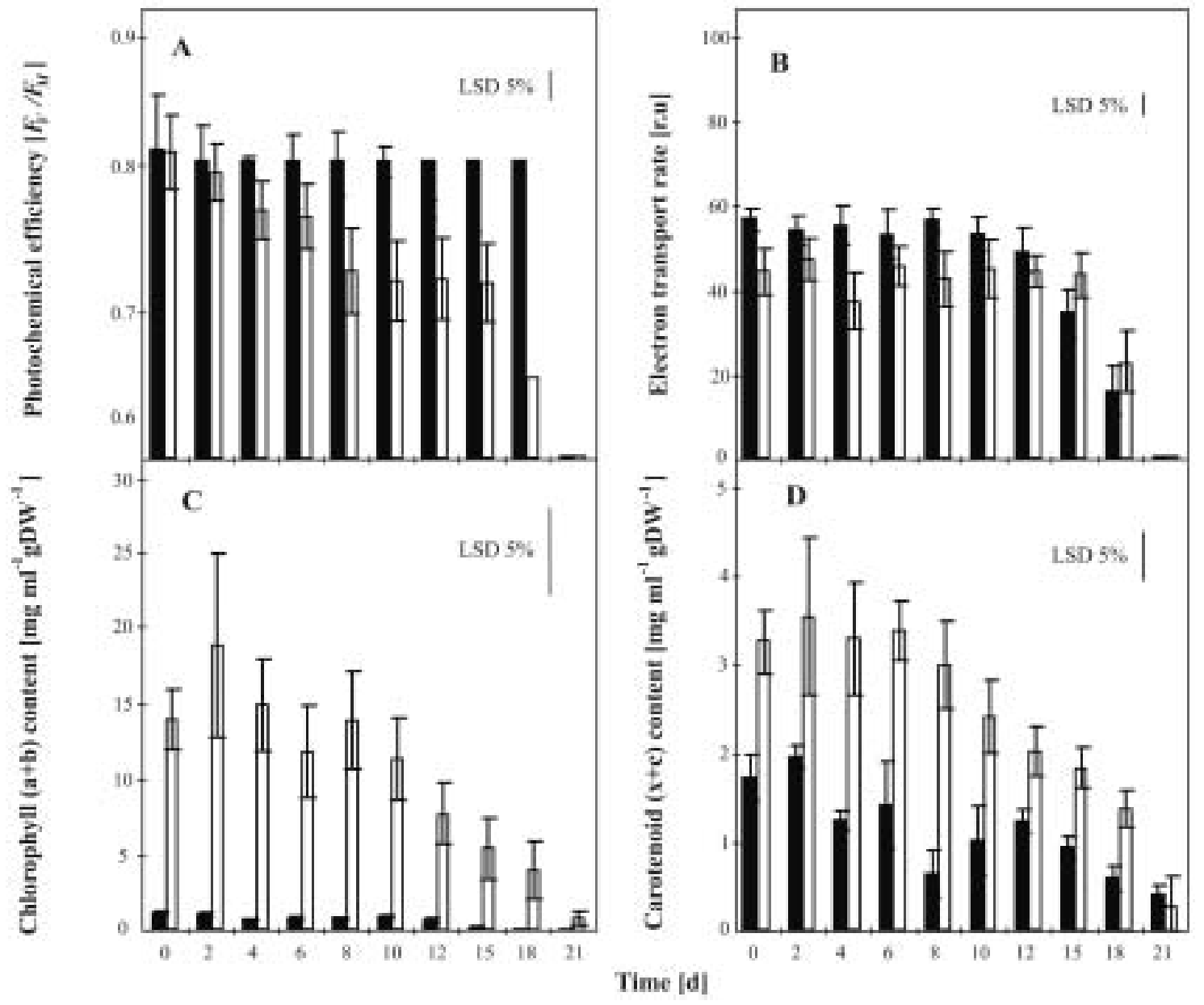

Fig. 2. Changes in fluorescence and pigment content of $X$. viscosa $(\mathbf{\square})$ and $D$. sanguinalis $(\square)$ leaves subjected to water deficit; (A) photochemical efficiency of PSII in the dark adapted conditions, $F_{\mathrm{V}} / F_{\mathrm{M}}$; (B) electron transport rate; $(C)$ chlorophyll $(a+b)$ content; $(D)$ carotenoid $(x+c)$ content. The error bars represent \pm SE.

These results alone propose a considerable damage to both species due to the decrease of photochemical efficiency of PSII, but PSII activity of $X$. viscosa was up-regulated when water was supplied again (data not shown).

\section{Pigment content}

The chlorophyll $(\mathrm{a}+\mathrm{b})$ and carotenoid $(\mathrm{x}+\mathrm{c})$ content of $D$. sanguinalis leaves decreased during the dehydration treatment (Fig. 2C and D). The chlorophyll $(\mathrm{a}+\mathrm{b})$ content of $D$. sanguinalis leaves decreased significantly after $10 \mathrm{~d}$ of water deficit treatment. On the other hand, in $X$. viscosa, the chlorophyll $(\mathrm{a}+\mathrm{b})$ content did not change significantly with increasing the time. The carotenoid $(\mathrm{x}+\mathrm{c})$ content of $X$. viscosa decreased significantly during the first $8 \mathrm{~d}$ and continued decreasing to $75 \%$ at the end of the experiment. There was no significant decrease in the carotenoid $(\mathrm{x}+\mathrm{c})$ content of $D$. sanguinalis leaves in the first $8 \mathrm{~d}$ of water deficit treatment. However, it significantly decreased at the end of the experiment. The dehydration probably limited the light harvesting capacity of the plant and induced chlorophyll degradation. The decline in the chlorophyll $(\mathrm{a}+\mathrm{b})$ and carotenoids content which may have contributed to the decrease in the photosynthesis rate was significantly higher in $D$. sanguinalis due to dehydration, whereas the chlorophyll content of $X$. vis$\cos a$ was not completely degraded. Leaf folding 
during dehydration of $X$. viscosa which is a poikilochlorophyllus species has been proposed to prevent light-chlorophyll interaction and damage while chlorophyll was still present. The decline in the carotenoid content suggests that these compounds do not serve a protective role in $X$. viscosa, possibly because of the efficiency mechanisms to prevent ROS formation in the first place and the operation of other antioxidant systems including anthocyanins.

The anthocyanin content of both species did not change significantly during the first $15 \mathrm{~d}$ of dehydration treatment (data not shown). However, the anthocyanin content of $D$. sanguinalis leaves increased significantly after day 15 . There were no significant changes in the anthocyanin content of $X$. viscosa during the treatment period. At the end of the treatment, the anthocyanin content of $D$. sanguinalis was five-fold higher than that of $X$. viscosa. The water deficit seems to limit the ability of $D$. sanguinalis to increase the carotenoids and anthocyanins contents as this could have acted as a potential protection against the oxidative damage, protecting the photosynthetic apparatus against ROS.

\section{Changes in the activity of antioxidant enzymes}

The activity of SOD and POD in $X$. viscosa and $D$. sanguinalis was analysed by native PAGE. The activity of individual antioxidant enzyme bands was quantified with the Syngene software programme using an imaging system. The dehydration treatment caused an increase in the activation of SOD enzymes in $X$. viscosa. In $X$. viscosa, the total SOD activity increased significantly from day 1 to day 18 of the treatment, compared to the untreated plants (Fig. 3A). At the end of the experiment, the total SOD activity in $X$. viscosa was significantly higher (2-fold) than in the control. In $D$. sanguinalis the total SOD activity did not significantly change during the dehydration treatment (Fig. 3A). The total SOD activity of $X$. viscosa leaves was higher than $D$. sanguinalis leaves throughout the treatment. At the end of the treatment the total SOD activity of $X$. viscosa was three-fold higher than that of $D$. sanguinalis. Water deficiency caused a marked increase in the total SOD activity in $X$. viscosa compared to $D$. sanguinalis. We propose that through a higher SOD activity the superoxide radicals in the chloro-

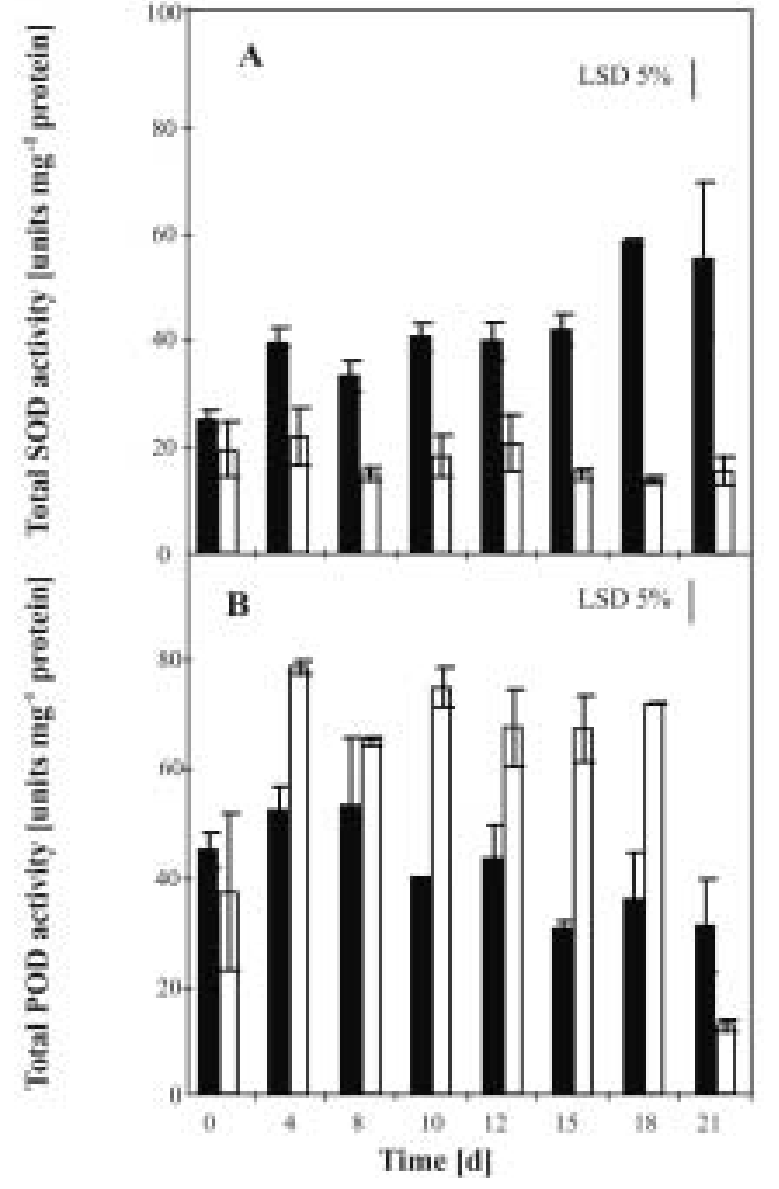

Fig. 3. Changes in total activity of the antioxidant enzymes (A) superoxide dismutase and (B) peroxidase during water deficit treatment in $X$. viscosa (ם) and $D$. sanguinalis $(\square)$. Error bars represent \pm SE.

plast are eliminated and oxidative damage through water deficit stress is significantly reduced.

Following an initial increase of total POD activity in $X$. viscosa (day $1-8$ ) the activity significantly decreased (Fig. 3B). Total POD activity of D. sanguinalis increased significantly at day 2. This was maintained until day 18 before it decreased significantly (Fig. 3B). The total POD activity in D. sanguinalis was higher than in $X$. viscosa. The observation that POD was only slightly decreased during the dehydration treatment suggests that the water deficit was not damaging for $X$. viscosa. The antioxidant enzyme activity of $X$. viscosa obtained in this study showed that its response to a water deficit was the same as the antioxidant enzyme behaviour of other resurrection plants in other 
studies. It has been reported that at least three antioxidant enzymes (SOD, GR and APX) are upregulated during water deficit in Xerophyta humilis (Farrant, 2000).

The resurrection plant $X$. viscosa acclimated to water deficit within the first 8-10 d. This resulted in a reduction in photosynthesis and an increase in SOD levels, with no ultimate apparent damage. Also the absence of increase in POD activity in $X$. viscosa suggests that there was no peroxidative damage of its membranes. After rewatering the desiccated plant rehydrated completely within $80 \mathrm{~h}$, resuming full physiological activities (results not shown). In case of $D$. sanguinalis, the water deficit induced considerable stress. The total activities of SOD decreased and of POD increased during the dehydration treatment in $D$. sanguinalis. This indicates a need for dealing with excess ROS. It is likely that its antioxidant systems (antioxidant enzymes and anthocyanins) were not sufficient to protect against photooxidation induced by water deficit. After rewatering of the desiccated D. sanguinalis the plant did not rehydrate and consequently died (results not shown). Even though an upregulation of protection mechanisms occured this was probably no adequate protection to prevent photooxidation induced by water deficit in that species.
Asada K. (1999), The water-water cycle in chloroplasts: Scavenging of active oxygens and dissipation of excess photons. Annu. Rev. Plant Physiol. Plant Mol. Biol. 50, 601-639.

Bowler C., Van Montagu M., and Inze D. (1992), Superoxide dismutase and stress tolerance. Annu. Rev. Plant Physiol. Plant Mol. Biol. 43, 83-116.

Bradford M. M. (1976), A rapid and sensitive method for the quantitation of microgram quantities of protein utilizing the principle of protein-dye binding. Anal. Biochem. 72, 248-254.

Burke J. J. and Oliver M. J. (1992), Differential temperature sensitivity of pea superoxide dismutase. Plant Physiol. 100, 1595-1598.

Ekmekci Y., Farrant J. M., Thomson J. A., and Mundree S. G. (2004), Antioxidant response and photosynthetic characteristics of Xerophyta viscosa Baker and Digitaria sanguinalis $\mathrm{L}$. leaves induced by high light. Israel J. Plant Sci. 52, 177-187.

Farrant J. M. (2000), A comparison of mechanisms of desiccation tolerance among three angiosperm resurrection plant species. Plant Ecol. 151, 29-39.

Foyer C. H. and Mullineaux P. (1994), Causes of Photooxidative Stress and Amelioration of Defense Systems in Plants. CRC Press, Boca Raton.

Garwe D., Thomson J. A., and Mundree S. G. (2003), Molecular characterization of $X V S A P 1$, a stress-responsive gene from the resurrection plant Xerophyta viscosa Baker. J. Exp. Bot. 54, 191-201.

Genty B., Briantais J. M., and Baker N. R. (1989), The relationship between the quantum yield of photosynthetic electron transport and quenching of chlorophyll fluorescence. Biochim. Biophys. Acta. 990, 87-92.

Jung S. (2004), Variation in antioxidant metabolism of young and mature leaves of Arabidopsis thaliana subjected to drought. Plant Sci. 166, 459-466.

Krause G. H. and Weis E. (1991), Chlorophyll fluorescence and photosynthesis: The basics. Annu. Rev. Plant Physiol. Plant Mol. Biol. 42, 313-349.
Laemmli U. K. (1970), Cleavage of structural proteins during the assembly of the head of bacteriophage T4. Nature 227, 680-685.

Lawlor D. H. (1995), The effects of water deficit on photosynthesis. In: Environment and Plant Metabolism Flexibility and Acclimation (Smirnoff N., ed.). BIOS Scientific Publishers, Oxford, pp. 129-156.

Lichtenthaler H. K. (1987), Chlorophylls and carotenoids, the pigments of photosynthetic biomembranes. Methods Enzymol. 148, 350-382

Lima A. L. S., DaMatta F. M., Pinheiro H. A., Totola M. R., and Loureiro M. E. (2002), Photochemical responses and oxidative stress in two clones of Coffea canephora under water deficit conditions. Environ. Exp. Bot. 47, 239-247.

Mancinelli A. L., Yang C. P. H., Lindquist P., Anderson O. R., and Rabino I. (1975), Photocontrol of anthocyanin synthesis III. The action of streptomycin on the synthesis of chlorophyll and anthocyanin. Plant Physiol. 55, 251-257.

Mowla S. B., Thomson J. A., Farrant J. M., and Mundree S. G. (2002), A novel stress-inducible antioxidant enzyme identified from the resurrection plant Xerophyta viscosa Baker. Planta 215, 716-726.

Mundree S. G. and Farrant J. M. (2000), Some physiological and molecular insights into the mechanisms of desiccation tolerance in the resurrection plant Xerophyta viscosa Baker. In: Plant Tolerance to Abiotic Stresses in Agriculture: Role of Genetic Engineering (Cherry J. H., Ryther A., and Locy R. D., eds.). Kluwer Academic Publishers, Dordrecht, The Netherlands, pp. 201-222.

Mundree S. G., Whittaker A.,Thomson J. A., and Farrant J. M. (2000), An aldose reductase homolog from the resurrection plant Xerophyta viscosa Baker. Planta 211, 693-700.

Ndima T., Farrant J., Thomson J., and Mundree S. G. (2001), Molecular characterization of XVT8, a stressresponsive gene from the resurrection plant Xero 
phyta viscosa Baker. Plant Growth Regul. 35, 137145.

Noctor G. and Foyer C. H. (1998), Ascorbate and glutathione: Keeping active oxygen under control. Annu. Rev. Plant Physiol. Plant Mol. Biol. 49, 249-279.

Pinheiro H. A., DaMatta F. M., Chaves A. R. M., Fontes E. P. B., and Loureiro M. E. (2004), Drought tolerance in relation to protection against oxidative stress on clones of Coffea canephora subjected to long-term drought. Plant Sci. 167, 1307-1314.

Ramachandra-Reddy A., Chaitanya K. V., Jutur P. P., and Sumithra K. (2004), Differential antioxidative responses to water stress among five mulberry (Morus alba L.) cultivars. Environ. Exp. Bot. 52, 33-42.

Rao V. M., Hale B. A., and Omrod D. P. (1995), Amelioation of ozone induced oxidative damage in wheat plants grown under high carbon dioxide. Plant Physiol. 109, 421-432.

Saccardy K., Pineau B., Roche O., and Cornic G. (1998), Photochemical efficiency of photosystem II and xanthophyll cycle components in Zea mays leaves exposed to water stress and high light. Photsynth. Res. 56, 57-66.
Sherwin H. W. and Farrant J. M. (1996), Differences in rehydration of three desiccation-tolerant angiosperm species. Ann. Bot. 78, 703-710.

Sherwin H. W. and Farrant J. M. (1998), Protection mechanisms against excess light in the resurrection plants Carterostigma wilmsii and Xerophyta viscosa. Plant Growth Regul. 24, 203-210.

Sionit M. and Patterson D. T. (1985), Responses of $\mathrm{C}_{4}$ grasses to atmospheric $\mathrm{CO}_{2}$ enrichment: I. Effect of water stress. Crop Sci. 25, 533-537.

Srivalli B., Sharma G., and Khanna-Chopra R. (2003), Antioxidative defense system in an upland rice cultivar subjected to increasing intensity of water stress followed by recovery. Physiol. Plant. 119, 503-512.

Tambussi E. A., Bartoli C. G., Beltrano J., Guiamet J. J. and Araus J. L. (2000), Oxidative damage to thylakoid proteins in water-stressed leaves of wheat (Triticum aestivum). Physiol. Plant 108, 398-404.

von Caemmerer S. and Farquhar G. D. (1981), Some relationships between the biochemistry of photosynthesis and gas exchange of leaves. Planta 153, 376-387. 